\title{
Prevalence of obstructive sleep apnea and central apnea in Overweight and Obese children
}

\author{
Nageswara Reddy Yamasani ${ }^{*}$, Naveen Kumar Reddy $\mathbf{A}^{1}$ \\ ${ }^{1}$ Dr Nageswara Reddy Yamasani, Assistant Professor, ${ }^{2}$ Dr Naveen Kumar Reddy, Assistant Professor, Both are affiliated \\ with Department of Paediatrics, Viswabharathi Medical College, Kurnool, Andra Pradesh, India
}

Address for Correspondence: Dr Nageswara Reddy Yamasani, Assistant Professor, Paediatrics, Viswabharathi Medical College, Kurnool, Andra Pradesh, Email:gonageswar@gmail.com

\begin{abstract}
Introduction: Obstructive sleep disordered breathing with snoring, breathing through the mouth, apnea during sleep is very common among children. Many of these children outgrow the condition as the symptoms are very mild and reduce with age. Enlargement of adenoids or tonsils can lead to tonsilolectomey and adenoidectomy, further leading to OSA. Materials and Methods: 46 obese or overweight children between the ages 3-15 years with suspected sleep apnea were subjected to vigorous physical and clinical examinations. Demographic details were noted apart from details such as sleep pattern, symptoms and snoring, daily routine, health history etc with reference to the Paediatric Sleep Questionnaire (PSQ). All the children underwent polysomnography testing, Apnea- Hypopnea Index (AHI), oxygen saturation, desaturation levels and sleep efficiency. Results: Out of the 46 children, 29 (59.2\%) were boys and 17 (40.8\%) were girls. The girls were older than the boys with their mean age being 8.6 in comparison to 5.9 of the boys. 31 patients were overweight and 15 were obese. Obstructive sleep apnea was observed in $18(39.1 \%)$ patients with 9 patients each presenting with mild OSA and moderate to severe OSA. Central apnea was observed in 4 obese and 2 overweight children. AHI and desaturation levels were significantly higher among the OSA patients than in the normal range in the other patients. Conclusion: Though all snoring cases may not be OSA but most of the OSA cases are associated with snoring, it is therefore advisable that all the snoring children with other presentation of SDB be screened for OSA and central apnea.
\end{abstract}

Keywords: Obstructive Sleep Apnea, Central Apnea, Obese children, Overweight Children

\section{Introduction}

Obstructive sleep disordered breathing is very common among children. Snoring, breathing through the mouth, apnea during sleep often prompts the parents to seek medical help. It is estimated that $3-12 \%$ of the children snore during sleep and $1-10 \%$ suffer from obstructive sleep apnea (OSA) [1-3]. In most of these children, the symptoms are very mild and have been observed to reduce with age. Many of the children outgrow the condition. Many a times, OSA results due to adenotonsillar hypertrophy, neuromuscular disease and craniofacial abnormalities [3]. When a child's breathing is disrupted, the body perceives this as a choking

Manuscript received: $26^{\text {th }}$ Nov 2015

Reviewed: $04^{\text {th }}$ Dec 2015

Author Corrected; $15^{\text {th }}$ Dec 2015

Accepted for Publication: 23th Dec 2015 phenomenon, thereby reducing the heart rate, increasing the blood pressure, activates and arouses the brain, hence disrupting the sleep. Oxygen levels also drop [4].

The children with sleep apnea syndromes often show a failure to thrive, some of them being below $25^{\text {th }}$ percentile by weight $[5,6]$.

The main cause is said to be occlusion of the upper respiratory tract associated with an upper airway anatomic abnormality like hyperplasia of the adenoid and/or tonsillar tissue as the major cause [5]. Sometimes, even $\mathrm{CO}_{2}$ retention and cardiovascular complications can take place [6,7]. Most of the time, this enlargement of adenoids or tonsils can lead to tonsillectomy and adenoidectomy, further leading to OSA [8-10]. The risk is higher in the overweight 
children because fat deposits around the neck and throat can also narrow the airway resulting in disordered breathing [4].

Sleep disordered breathing in children is a public health problem, especially due to the increasing rates of obesity and hyperactivity. It has been reported that the underlying sleep disordered breathing was observed in a large percentage of children with hyperactivity and inattentive [11].

This study was conducted to identify the prevalence of disordered breathing in sleep and obstructive sleep apnea in our area.

\section{Materials and Methods}

This study was conducted in the department of Pediatrics at Viswabharathi Medical College during the period of 2 years. 46 obese or overweight children between the ages 3-15 years with suspected sleep apnea were included into the study. All the children were subjected to complete physical and clinical examinations. Demographic details such as age, sex, weight, height and BMI were noted. Details such as sleep pattern, symptoms and snoring, daily routine, health history etc were noted with reference to the Paediatric Sleep Questionnaire (PSQ).
Further, questions on tonsillectomy, adenoidectomy were also asked. Details on smokers at home, infection of the child with tonsillitis, otitis media, bronchitis, cold etc were also noted.

All the children underwent polysomnography testing. The scoring of the electronic data was performed manually in accordance to the established criteria. Sleep time (in minutes) was estimated the following morning on the estimation of parents/nurses and the Static Charge sensitive bed (SCSB).

Arterial oxygen saturation (SaO2) was measured simultaneously with both a finger and a flex probe with two pulse oximeters. OSA was defined according to the International Classification of Sleep Disorders and classified as per American Academy of Sleep Medicine (AASM) criteria [12]. A AHI greater than 1 (Average: 0.1-0.5 events per hour) or a minimum oxygen saturation of less than $92 \%$ was considered abnormal. The Apnea - hypopnea index (AHI) was calculated as number of apneas and hypopneas per hour of sleep. Sleep efficiency, arousal Index were also identified.

Blood samples were taken in the morning for measuring the thyroid-stimulating hormone levels and other routine blood values.

\section{Results}

Out of the 46 children, 29 (59.2\%) were boys and 17 (40.8\%) were girls. The girls were older than the boys with their mean age being 8.6 in comparison to 5.9 of the boys. The general demographic details is given in Table:1. 31 patients were overweight and 15 were obese

\section{Table-1: Demographic details of the patients}

\begin{tabular}{|c|c|c|}
\hline 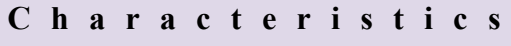 & B $\quad \mathbf{0} \quad \mathbf{y}$ & $\mathbf{r} \quad \mathbf{l} \mathbf{s}$ \\
\hline $\mathrm{O}$ v e $\mathrm{r}$ w e i g h t $\quad(\mathrm{n}=31)$ & $20(64.5 \%)$ & $11(35.5 \%)$ \\
\hline $\mathrm{O} b$ e $\mathrm{s}$ e $\quad(\mathrm{n}=15)$ & $9 \quad\left(\begin{array}{lll}6 & 0 & \%\end{array}\right)$ & $6 \quad\left(\begin{array}{lll}4 & 0 & \%\end{array}\right)$ \\
\hline M e a $n$ a $g$ e ( i n y e a r s ) & $5.9 \pm 2.1$ & $8.6 \pm 4.3$ \\
\hline $\mathrm{P}$ a $\mathrm{s}$ s $\mathrm{i} v \mathrm{e} \quad \mathrm{s} \mathrm{m}$ o $\mathrm{k}$ i $\mathrm{ng}$ & $17(58.6 \%)$ & $12(70.6 \%)$ \\
\hline 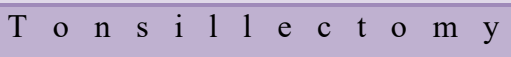 & $1(3.4 \%)$ & $1(5.9 \%)$ \\
\hline A $d$ e $n$ o $i$ d e c t o $m$ y & $8(27.6 \%)$ & $4(23.5 \%)$ \\
\hline
\end{tabular}

Of the symptoms that were observed at the time of presentation, the most common was troubled sleep followed by sleeping in the afternoon by 23 children. 19 children showed decreased performance at school due to exhaustion. 9 of these children were sleepy during the day also (Fig:1). 


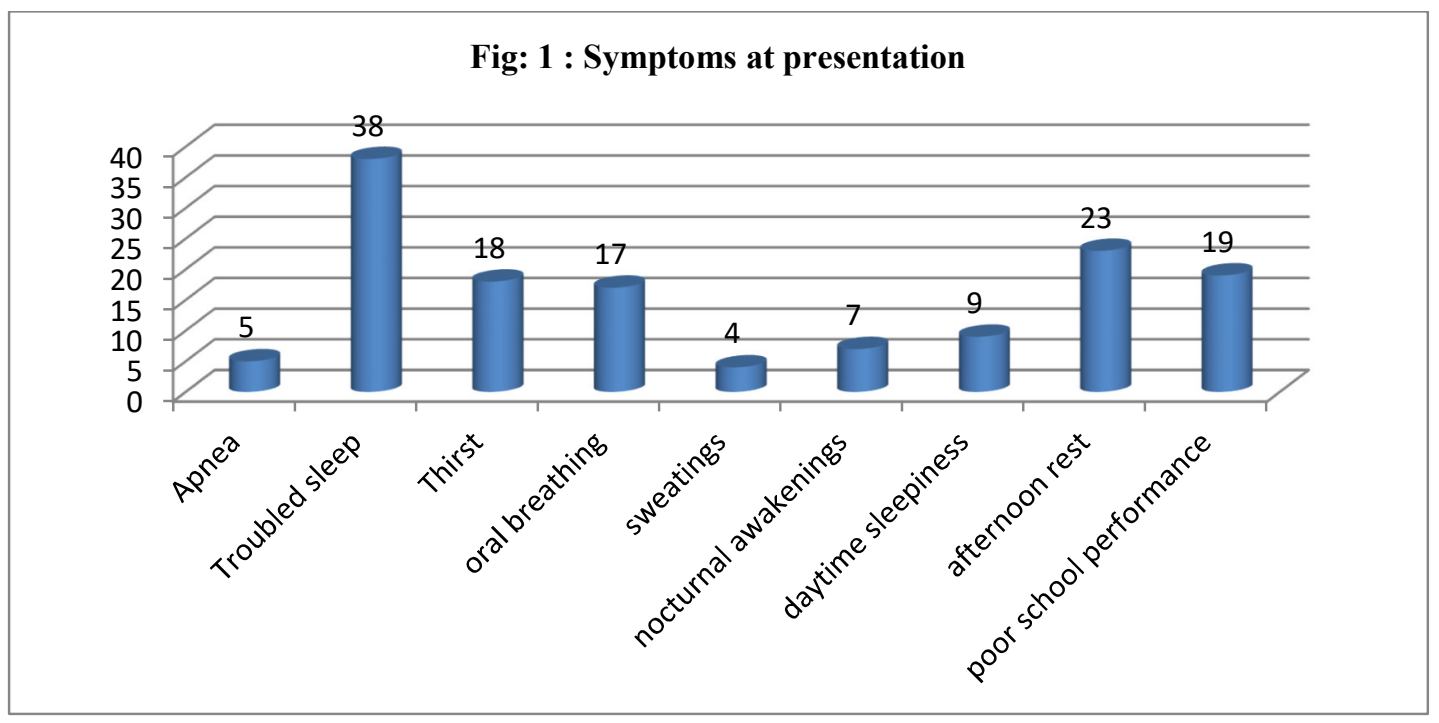

Obstructive sleep apnea was observed in 18 (39.1\%) patients among whom mild OSA was seen in 9 children and similar was the case with moderate to severe OSA with 9 children. Central apnea or total absence of breathing was observed in 6 children among which, 4 were obese and 2 were overweight (Table: 2)

Table-2: Presence of snoring and apnea in overweight and obese children

\begin{tabular}{|c|c|c|c|}
\hline & $\begin{array}{l}\text { O v e r w e i g t } \\
\text { C h i } 1 \text { d e n } \\
(\mathrm{n}=31)\end{array}$ & 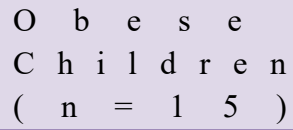 & $\begin{array}{l}\text { T } \mathrm{o} \quad \mathrm{t} \quad \mathrm{a} \\
(\mathrm{n}=46)\end{array}$ \\
\hline $\begin{array}{llllll}\mathrm{N} & \mathrm{o} & \mathrm{r} & \mathrm{m} & \mathrm{a} & 1\end{array}$ & 1 & 5 & 1 \\
\hline $\begin{array}{lllllll}\mathrm{S} & \mathrm{n} & \mathrm{o} & \mathrm{r} & \mathrm{i} & \mathrm{n} & \mathrm{g}\end{array}$ & 5 & 2 & 7 \\
\hline $\mathrm{M}$ i $1 \mathrm{l}$ d $\quad \mathrm{O} \quad \mathrm{S} \quad \mathrm{A}$ & 6 & 3 & 9 \\
\hline Moderate to severe OSA & 7 & 2 & 9 \\
\hline Central Apnea & 2 & 3 & 5 \\
\hline
\end{tabular}

There was no difference in the total sleep time, REM and sleep efficiency among all the children. AHI was significantly higher among the OSA patients while in the normal range in the other patients. The desaturation index was also higher in the OSA and Central apnea children while they were in the normal range in Normal and snoring children (Table:3).

\section{Table- 3: Sleep indices in children}

\begin{tabular}{|c|c|c|c|c|c|c|c|c|c|c|c|c|c|c|c|c|c|c|c|c|}
\hline & $\mathrm{N}$ & o & $\mathrm{m}$ & 1 & S & n o & $\mathrm{r}$ i & $\mathrm{g}$ & & i 1 & $\mathrm{O}$ & A & & lerate & sever & & & $n$ tr & al ap & \\
\hline Total Sleep time in (hrs) & 7 & . & 4 & & 7 & & . & 1 & 7 & & & 5 & 7 & & . & 4 & 7 & & . & 8 \\
\hline REM ( $\%$ of TST) & 2 & & & 2 & 2 & & & 1 & 2 & 0 & - & 9 & 2 & & & 1 & 2 & & & 3 \\
\hline Sleep efficiency & 8 & 8 & 4 & $\%$ & 8 & 4 & 2 & $\%$ & 8 & 5 & 1 & $\%$ & 8 & 4 & 4 & $\%$ & 8 & 2 & 8 & $\%$ \\
\hline $\mathrm{H}$ & 0 & . & 4 & 5 & 0 & . & 3 & 3 & 1 & . & 4 & 5 & 1 & . & 6 & 5 & 0 & & 6 & 7 \\
\hline $\mathrm{SaO} 2$ nadir $(\%)$ & 9 & 4 & . & 3 & 8 & 8 & . & 3 & 8 & 3 & . & 1 & 8 & 3 & . & 3 & 8 & & & 4 \\
\hline $\mathrm{Me}$ a $\mathrm{S} \mathrm{S}$ a O 2 & 9 & 6 & . & 2 & 9 & 6 & . & 9 & 9 & 5 & . & 7 & 9 & 6 & . & 1 & 9 & 4 & . & 1 \\
\hline Desaturation Index & 0 & & & 5 & 1 & & & 3 & 4 & & & 1 & 4 & & & 2 & 4 & & & 7 \\
\hline
\end{tabular}

\section{Discussion}

The prevalence of OSA among children is said to be lesser than that in adults[12-14]. The rate was similar in studies of snoring children preoperatively $[8,10]$ and a higher prevalence was observed in children with Down's syndrome[15]. 
There were more number of boys affected by sleep disorders compared to the girls although girls were older than the boys. A similar result was observed in a study by Gislason et al who also found girls to be older than boys among children suffering from apneic episodes [22].

Brunetti et al also reported the younger children were at a greater risk of OSA than the older ones because of the volumetric adenoids/rhinopharynx ratio varies and the obstruction is easily caused in the younger ones than the older children $[23,24]$.

We were unable to study this aspect as our sample size was too small. The prevalence of OSA was found to be similar in boys and girls in a study by Anuntaseree et al [27].

The symptoms at the time of presentation were most commonly troubled sleep with many of the children taking afternoon rest due to exhaustion. Nocturnal sweating was also seen in a few patients with thirst and oral breathing to be other common complaints.

Many of the children did poorly in school due to the insufficient sleep. A similar presentation was reported in a study by Brunetti et al with troubled sleep, nocturnal sweating, and oral breathing being significantly more frequent than other symptoms among the children with OSA [23].

In our study, the prevalence of OSA among children in our study was $32.6 \%$. it should be considered that we had taken into account only the symptomatic, overweight and obese children so the prevalence is higher.

Prevalence of OSA was observed in $41.9 \%$ of the overweight children and in $33.3 \%$ of the obese children. This higher prevalence of OSA in overweight children rather than obese were corroborated by other similar studies also [16-21].

We had observed a prevalence of central apnea in $10.9 \%$ of the cases. This result was slightly lower than a similar study by Verhulst et al [16]. As in their study our study also showed it to be associated with serious desaturation, as was also reported by Marcus et al[20].

The body mass index among the children were considerably lower than that of the adults. And there seemed to be no significant difference to the fat and
OSA among the children when compared to the adults. Although we had very few cases of enlarged tonsils, they seem to be a major rsik facor for OSA which was in agreement to studies by Verhulst et $\mathrm{al}^{16}$ and Wing et al [21].

The AHI index was higher among the OSA patients with most of them showing more than 3 episodes per hour which was associated with $>4 \%$ oxygen desaturation. Similar results were noted in the study by Gilason et al [22].

It is important to identify the predictors of OSA, which we have shown to be snoring, nocturnal sweating, oral breathing and daily sleepiness as was corroborated in earlier studies [25]. Passive smoking in the children also seems to be an important factor in OSA which was corroborated by Corbo et al [26].

\section{Conclusion}

The prevalence of Sleep Disorder Breathing and OSA is highly prevalent among the obese and the overweight children, which may lead to various complications in future. Though all snoring cases may not be OSA but most of the OSA cases are associated with snoring, It is therefore advisable that all the snoring children with other presentation of SDB be screened for OSA and central apnea.

\section{References}

1. Owen GO, Canter RJ, Robinson A. Overnight pulse oximetry in snoring and non-snoring children. Clin Otolaryngol Allied Sci. 1995 Oct;20(5):402-6.

2. Elisabeth Hultcrantz and B Lofstrand Tidestrom, The development of sleep disordered breathing from 4 to 12 years and dental arch morphology, 2009, INTERNATIONAL JOURNAL OF PEDIATRIC OTORHINOLARYNGOLOGY, (73), 9, 1234-1241. http://dx.doi.org/10.1016/j.ijporl.2009.05.012

3. Ferreira AM, Clemente V, Gozal D, Gomes A, Pissarra C, César H, Coelho I, Silva CF, Azevedo $\mathrm{MH}$. Snoring in Portuguese primary school children. Pediatrics. 2000 Nov;106(5):E64.

4. http://www.entnet.org/content/pediatric-sleepdisordered-breathingobstructive-sleep-apnea

5. Guilleminault C, Stoohs R. Chronic snoring and obstructive sleep apnea syndrome in children. Lung. 1990;168 Suppl:912-9. 
6. Lind MG, Lundell BP. Tonsillar hyperplasia in children. A cause of obstructive sleep apneas, CO2 retention, and retarded growth. Arch Otolaryngol. 1982 Oct;108(10):650-4.

7. Wilkinson AR, McCormick MS, Freeland AP, Pickering D. Electrocardiographic signs of pulmonary hypertension in children who snore. Br Med J (Clin Res Ed). 1981 May 16;282(6276):1579-81.

8. Stradling JR, Thomas G, Warley AR, Williams P, Freeland A. Effect of adenotonsillectomy on nocturnal hypoxaemia, sleep disturbance, and symptoms in snoring children. Lancet. 1990 Feb 3;335(8684):249-53.

9. Croft CB, Brockbank MJ, Wright A, Swanston AR. Obstructive sleep apnoea in children undergoing routine tonsillectomy and adenoidectomy. Clin Otolaryngol Allied Sci. 1990 Aug;15(4):307-14.

10. Svanborg E, Larsson H, Carlsson-Nordlander B. Indications of sleep-related upper airway obstruction in children. In: Peter JH, Penzel T, Podszus T, von Wichert P, eds. Sleep. Berlin: Springer-Verlag, 1991; 468-75

11. Chervin RD, Archbold KH, Dillon JE, Panahi P, Pituch KJ, Dahl RE, et al. Inattention, hyperactivity, and symptoms of sleep-disordered breathing. Pediatrics. 2002;109:449-56.

12. Epstein LJ, Kristo D, Strollo PJ Jr, Friedman N, Malhotra A, Patil SP, Ramar K, Rogers R, Schwab RJ, Weaver EM, Weinstein MD; Adult Obstructive Sleep Apnea Task Force of the American Academy of Sleep Medicine. Clinical guideline for the evaluation, management and long-term care of obstructive sleep apnea in adults. J Clin Sleep Med. 2009 Jun 15;5(3):263-76.

13. Young T, Palta M, Dempsey J, et al. The occurrence of sleepdisordered breathing among middle-aged adults. N Engl J Med 1993; 328:1230-52

14. Gislason T, Almqvist M, Eriksson G, Taube A, Boman G. Prevalence of sleep apnea syndrome among Swedish men--an epidemiological study. J Clin Epidemiol. 1988;41(6):571-6.

15. Gislason $\mathrm{T}$, Benediktsdóttir $\mathrm{B}, \mathrm{Björnsson}$ JK, Kjartansson G, Kjeld $\quad$ M, Kristbjarnarson $\quad H$. Snoring, hypertension, and the sleep apnea syndrome. An epidemiologic survey of middle-aged women. Chest. 1993 Apr;103(4):1147-51.
16. Stebbens VA, Dennis J, Samuels MP, Croft CB, Southall DP. Sleep related upper airway obstruction in a cohort with Down's syndrome. Arch Dis Child. 1991 Nov;66(11):1333-8.

17. Gislason T, Benediktsdóttir B. Snoring, apneic episodes, and nocturnal hypoxemia among children 6 months to 6 years old. An epidemiologic study of lower limit of prevalence. Chest. 1995 Apr;107(4):963-6.

18. Brunetti L, Rana S, Lospalluti ML, Pietrafesa A, Francavilla R, Fanelli M, Armenio L. Prevalence of obstructive sleep apnea syndrome in a cohort of 1,207 children of southern Italy. Chest. 2001 Dec;120(6):1930-5.

19. Fernbach SK, Brouillette RT, Riggs TW, Hunt CE. Radiologic evaluation of adenoids and tonsils in children with obstructive sleep apnea: plain films and fluoroscopy. Pediatr Radiol. 1983;13(5):258-65.

20. Anuntaseree W, Rookkapan K, Kuasirikul S, Thongsuksai P. Snoring and obstructive sleep apnea in Thai school-age children: prevalence and predisposing factors. Pediatr Pulmonol. 2001 Sep;32(3):222-7.

21. Verhulst SL, Schrauwen N, Haentjens D, Suys B, Rooman RP, Van Gaal L, De Backer WA, Desager $\mathrm{KN}$. Sleep-disordered breathing in overweight and obese children and adolescents: prevalence, characteristics and the role of fat distribution. Arch Dis Child. 2007 Mar;92(3):205-8. Epub 2006 Oct 13.

22. Mallory GB Jr, Fiser DH, Jackson R. Sleepassociated breathing disorders in morbidly obese children and adolescents. J Pediatr. 1989 Dec;115(6):892-7.

23. Silvestri JM, Weese-Mayer DE, Bass MT, Kenny AS, Hauptman SA, Pearsall SM. Polysomnography in obese children with a history of sleep-associated breathing disorders. Pediatr Pulmonol. 1993 Aug;16(2):124-9.

24. Chay OM, Goh A, Abisheganaden J, Tang J, Lim WH, Chan YH, Wee MK, Johan A, John AB, Cheng HK, Lin M, Chee T, Rajan U, Wang S, Machin D. Obstructive sleep apnea syndrome in obese Singapore children. Pediatr Pulmonol. 2000 Apr;29(4):284-90.

25. Marcus CL, Curtis S, Koerner CB, Joffe A, Serwint JR, Loughlin GM. Evaluation of pulmonary function 


\section{Research Article}

and polysomnography in obese children and adolescents. Pediatr Pulmonol. 1996 Mar;21(3):176-83.

26. Wing YK, Hui SH, Pak WM, Ho CK, Cheung A, Li AM, Fok TF. A controlled study of sleep related disordered breathing in obese children. Arch Dis Child. 2003 Dec;88(12):1043-7.
27. Owens J, Opipari L, Nobile C, Spirito A. Sleep and daytime behavior in children with obstructive sleep apnea and behavioral sleep disorders. Pediatrics. 1998 Nov;102(5):1178-84.

28. Corbo GM, Fuciarelli F, Foresi A, De Benedetto F. Snoring in children: association with respiratory symptoms and passive smoking. BMJ. 1989 Dec $16 ; 299(6714): 1491-4$.

\section{How to cite this article?}

Nageswara Reddy Yamasani, Naveen Kumar Reddy A. Prevalence of obstructive sleep apnea and central apnea in Overweight and Obese children. Pediatr Rev: Int J Pediatr Res 2016;3(1):57-62.doi:10.17511/ijpr.2016.i01.11 